\title{
JUURNAL.RU
}

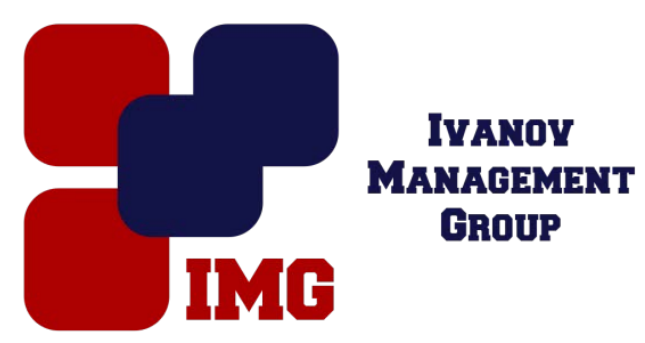

Кравченко А.И. Московский государственный университет им. М.В.Ломоносова Москва, Россия

doi: 10.18411/lj-30-04-2017-2-07

idsp 000001:lj-30-04-2017-2-07

\section{Генезис социальной структуры в России}

Старый средний класс подобно историческому центру города образовался чуть ли не в древние времена. Когда Аристотель писал о среднем классе, то он включал в его состав, в том числе ремесленников. В Средневековье ремесленники, лавочники и купцы, а также небольшая прослойка интеллигенции (врачи, учителя, преподаватели ВУЗов, художники, музыканты, артисты и др.) составляли основу старого среднего класса.

Великая индустриальная революция XVIII века внесла определенные коррективы в состав старого среднего класса, разбавив его отчасти рабочей аристократией. Однако основной удар по старому среднему классу нанесла современная технологическая революция, произошедшая во второй половине $\mathrm{XX}$ века. Появление наукоемких технологий и авангардных индустрий, в том числе электроники, авиакосмической и т.д., во-первых, вытеснило из рядов среднего класса старые слои ремесленников и купцов; во-вторых, привело к пополнению среднего класса новыми профессиональными слоями, в том числе менеджерами, инженерами, программистами, дизайнерами и т.д.

В зарубежной социологии новый средний класс считается: а) порождением; б) признаком постиндустриального общества.

Западные социологи склонны видеть в появлении многочисленного среднего класса основное доказательство исторических преимуществ: а) рыночного общества; б) демократии. Они полагают, что только капитализм заинтересован в быстром развитии наукоемкого производства, позволяет повысить материальный уровень широких слоев населения и приобщить их к благам 
современной цивилизации, в том числе сделать доступным высшее и среднее образование.

В постиндустриальном обществе главным достоянием по мнению Западных социологов становится не денежный капитал и собственность на материальные средства производства, а так называемый интеллектуальный капитал. Его главными составляющими являются знание и высокая квалификация.

Поскольку современная промышленность и общественное производство в целом все больше отходят от крупномасштабных организаций в сторону малого бизнеса, то в среднем классе ведущие позиции начинает занимать категория так называемых самозанятых или самонанятых работников. Рассмотрим, что это такое.

Капитализм, пришедший на смену феодализму, дал человечеству совершенно новую категорию населения - наемных работников. Это политически и юридически самостоятельная категория населения, способная за деньги продавать свой труд, - физический (рабочий класс) и умственный (интеллигенция). Продажа своего труда за деньги означает, что данная категория населения обладает экономической самостоятельностью. Но иначе решается вопрос об организационной самостоятельности.

В массовом или конвейерном производстве рабочий не является организационно-автономным, поскольку планирование его труда, режим работы и размер заработка определяет не он сам, а администрация. Кроме того, рабочие на конвейере считаются технологически привязанными к своему рабочему месту. Именно поэтому их часто называют придатками машины. Иными словами рабочий человек является функциональным продолжением станка или агрегата, за которым он трудится.

Если рабочие в массовом производстве потеряли свою организационную автономию, то другая часть наемных работников, а именно интеллигенция, сумела еe сохранить. Речь идет прежде всего о так называемой гуманитарной интеллигенции, т.е. адвокатах, врачах, преподавателях и т.д., которые не являются служащими крупных корпораций и компаний. Они занимаются самостоятельной практикой, имеют свой бизнес, обладают университетским образованием и получили лицензию на ведение самостоятельной практики. Таких работников зарубежной социологии именуют профессионалами.

Таким образом, мы видим, что структура среднего класса на Западе является зеркальным отражением структуры общественного производства, характерного для капитализма, находящегося на своей высшей постиндустриальной фазе. 
Гораздо сложнее решается вопрос о среднем классе применительно к российскому обществу. Поскольку в нашей стране в развитии капитализма отсутствовала историческая преемственность, то и в динамике среднего класса такой преемственности не наблюдается. Как мы с вами раньше отмечали, в российском обществе существовала не единая восходящая стратегия развития капитализма, а три попытки утвердить капитализм, предпринимавшиеся в разное историческое время.

Первая попытка была предпринята в эпоху первой модернизации царем Петром I. Задумав построить или перестроить российское общество по образу и подобию западного, Петр провел ряд кардинальных реформ, затрагивающие не только политическую и культурную сферы общества, но также экономическую и социальную.

Усилиями Петра I и Екатерины II Россия пыталась ускоренно выйти из пут феодального общества и провести у себя индустриализацию по западному образцу. В короткие по историческим меркам сроки Россия сумела создать достаточно развитую промышленность и обеспечить ее соответствующими финансовыми институтами. Однако развитие экономического базиса общества происходило под сильным влиянием и нажимом политических задач. Укрепление самодержавия и превращение России в великую державу поставило обоих царей перед такими историческими задачами, решение которых повлияло не только на социально-экономическое устройство общества, но и жестко предопределило его последующую историческую судьбу.

Первая задача - создание военно-промышленного комплекса (ВПК), который мог бы обеспечить России внешнеполитическую независимость. Вторая задача - укрепление властной вертикали, которое позволило бы придать российскому обществу внутриполитическую стабильность и целостность.

Если решение первой задачи привело к решающему преобладанию государственного сектора экономики над частным, то решение второй позволило создать в России уникальное явление - административную систему власти, состоящую из назначаемых сверху государственных чиновников. Конкурентный и отбор и мнение избирателей, которые в западной демократии выступают ключевыми институтами подбора управленческих кадров, в российском обществе отсутствовали. Директивный подбор кадров и назначение государственных чиновников сверху получило специальное название номенклатуры. Ее характерная черта заключается в том, что авторитарный стиль руководства превращается в структурную компоненту власти и перестает зависеть от личных качеств 
руководителя. Иными словами, каким бы демократическим по своим убеждениям ни был руководитель или чиновник, благодаря особенностям управленческой иерархии он вынужден придерживаться авторитарных методов руководства.

Совпадение двух отмеченных выше тенденций - развитие ВПК с преобладанием государственного сектора и становление административной системы в рамках одного общества свидетельствует о том, что в России не было того типа капитализма, который в это время формировался на Западе. Для западного общества характерны как раз обратные тенденции, а именно преобладание частного сектора над государственным и постепенная победа демократических форм правления над авторитарными.

Проведя сравнительно исторический анализ генезиса русского капитализма в XVIII - XIX вв. Мы можем заключить, что российское общество являлось капиталистическим скорее по форме, нежели по содержанию. Доказательством этому служат особенности становления русской буржуазии и средних классов.

М. И. Туган-Барановский, автор знаменитой книги «Русская фабрика», а также другие отечественные ученые раскрыли нам историческое своеобразие социальной структуры нашего общества.

В России существовали два явления, отсутствовавшие в Западном обществе:

口 дворянская буржуазия;

в крепостная буржуазия.

Остановимся на них подробно. Первая представляет собой прослойку преимущественно крупных и родовитых помещиков, которые в петровскую, и еще больше в екатерининскую эпоху стали активно втягиваться в бизнес, создавая в своих поместьях промышленные предприятия. Поскольку в России в обозначенную эпоху отсутствовал развитой капиталистический класс, то Петру I и Екатерине II в проведении своих буржуазных реформ можно было опереться только на русское дворянство.

Но как мы с вами знаем, сила дворянства проистекает от земли, а не от ее капитала, поэтому ее экономические интересы лежат в аграрной, а не промышленной сфере. Русское дворянство ни экономически, ни политически, ни социально не было заинтересовано в развитии нового общественного строя, который как оно смутно догадывалось, приведет к их уничтожению. Принудить силой дворянство заниматься промышленностью просвещенные монархи, каковыми себя считали западники Петр I и Екатерина II не могли. Оставалось одно - заинтересовать их. И для того существовал прекрасный механизм государственная казна. 
Читая исторические хроники, мы можем наблюдать, в каком количестве русскими царями раздавались указы от строительства промышленных объектов силами дворянства. Помимо официально выдаваемых заказов пристроившиеся к властной вертикали чиновники выуживали из казны огромные средства неофициальным путем, т.е. злоупотребляя служебным положением. Развитию особого типа промышленности в России благоприятствовало и то обстоятельство, что в руках дворянства была сконцентрирована дешевая рабочая сила крепостные крестьяне.

В отличие от Запада в России ни в XVIII, ни в первой половине XIX века не существовало рынка наемной рабочей силы. Формально крепостные крестьяне превращались в промышленных рабочих, юридически оставаясь собственностью помещиков или государства. В качестве зарплаты им засчитывались те недоимки, которые у них появлялись вследствие недовыполнения своих феодальных повинностей. Естественно, что дешевая рабочая сила была самой неквалифицированной и непроизводительной. Низкая производительность труда и невысокое качество продукции с тех пор стали исторической отличительной чертой отечественного производства.

Крепостная же буржуазия, в отличие от дворянской, формировалась не в верхах, а в низах российского общества. Талантливые и предприимчивые крестьяне, стремясь выбраться из нужды и накопить собственные капиталы, создавали в своих избушках-светелках примитивные производства - ядро будущей ткацкой промышленности. Постепенно, благодаря их трудолюбию и капиталистической сметке, семейные хозяйства превращались в настоящие капиталистические фабрики, на которых трудилась наемная рабочая сила из числа таких же крепостных крестьян. Поскольку у крестьянина перед крестьянином не может быть феодальных обязанностей, то заработная плата в этом случае выплачивалась деньгами. Помещику, в чьей собственности находились крепостные предприниматели, было выгодно не только помогать такому развитию, но и не отпускать на свободу крестьян-предпринимателей. Как только крестьяне-предприниматели превращались в миллионеров, цена выкупа на свободу многократно возрастала. У графа Шереметева находилось несколько сот таких крепостных предпринимателей. Получив выкуп со своих крестьян, Шереметев сказочно разбогател.

Кузницей крепостных капиталистов в России является город ИвановоВознесенск - центр текстильной промышленности. Именно оттуда и вышел Савва Морозов, основавший одну из крупнейших капиталистических династий. 
Если мы сравним нынешний этап развития капитализма с Екатерининской эпохой, то убедимся, что раньше государство проводило более мудрую экономическую политику. Ее главное достоинство заключается в том, что государство позволяло своим налогоплательщикам прежде напитаться экономическими соками, а затем уже увеличивать поборы с них. Сегодня тенденция противоположная.

Вторая попытка, или второй этап утверждения капитализма в России, происходил, как мы знаем, с 1921 года по 1929-31 годы. Как и прежде, государство освободило частную инициативу не по доброй воле, а по исторической необходимости.

Большевики уничтожили кадровый состав прежней властной вертикали, но не ее сущность. Административная система под патронажем государства, благодаря новым кадрам раскрутилась с еще большей силой. Партийные государственные чиновники, злоупотребляя служебным положением, за взятки раздавали государственные заказы на строительство промышленных объектов или протежировали им дополнительными льготами и привилегиями. Попытка создать карманный частный сектор, который полностью закрывал прореху в государственном секторе, смог бы накормить страну и одновременно оставался под полным контролем государства не удалась.

Если мы почитаем исторические хроники, то с удивлением обнаружим, каких грандиозных размеров приняло растление нравов в эпоху НЭПа. Самое удивительное в том, что первыми начали разлагаться комсомольские и партийные работники - вчерашние выходцы из рабочих, крестьян и низов той части русской буржуазии, которая уцелела после опустошительной гражданской войны. Предаваться потребительству для них было не новым делом, собственно большевики и не заботились о деградации буржуазного класса. Они знали, что капитализм допущен на короткое время. Однако вырождение партийных функционеров обеспокоило их не на шутку.

Второй раз в истории нашей страны мы наблюдаем удивительное явление: государственные служащие, не покидая своих постов, превращаются в теневых бизнесменов. Совмещение несовместимого, а именно службы государству и службы частному капиталу еще раз встретится нам в 90-е годы XX века. Провал второй попытки родить капитализм объясняется также недовольством народных масс. Крестьянство и рабочие, воевавшие в Красной Армии и проливавшие свою кровь за общество всеобщего равенства, демобилизовавшись и вернувшись с фронта, обнаружили в тылу вопиющее неравенство: ожившая в годы НЭПа мелкая 
буржуазия, как городская, так и сельская, успела превратить своих холопов в тех домочадцев, которых оставили красноармейцы. Таким образом, разочарованные красные воины через четыре года застали то общество, против которого они воевали.

Дневниковые записи Артёма Веселого, объездившего всю Центральную Россию и Поволжье, доносят до нас документальные записи тех жалоб и писем, которые посылали красноармейцы в центральные органы власти. Основной призыв - «Уничтожить гидру капитализма в тылу».

Таким образом, ограниченное введение капитализма в эпоху НЭПа позволило решить тактические задачи (накормить страну), но не позволило решить экономические задачи (построить общество социальной справедливости, ради которого совершалась октябрьская революция). Великий перелом 1921 года был исторически неизбежен, но экономически неоправдан. Две попытки создать капитализм в России так и не решили главную историческую задачу - построить средний класс. Решение этой задачи было возложено на советское государство и строительство социализма.

В течение семидесятилетнего периода укрепления советской власти в нашем обществе происходило два важных процесса:

\section{Кристаллизация стратификационной системы;}

Становление среднего класса.

Расцвет или наивысшая точка в том или другом процессе приходится на 1970-80-е годы. Кристаллизация означает «упаковывание» людей по своим социальным слоям и классам. Стратификацию можно мыслить в двух состояниях жидком и в твердо кристаллическом.

Из физики нам известно, что жидкие кристаллы представляют собой хотя и структурированные, но гибкие и подвижные системы. Такой системой было советское общество на протяжении первых пятидесяти лет. Американские социологи, в частности А. Инкельс, написавшие книги в начале 1960-х годов, отмечали, что советское общество наряду с американским является самым мобильным. Действительно, после 1917 года была сломана старая социальная структура, в которой вакантными оказались высшие и средние позиции. В течение первых 10-15 лет эти вакансии занимали представители низших классов выходцы из рабочих и крестьян. Министрами, директорами, руководителями учреждений становились партийные рабочие крестьян, прославившиеся на фронтах Гражданской войны. Появившееся в конце 20-х годов выражение «красные директора» фиксирует тот факт, что к руководству народным 
хозяйством пришло новое поколение руководителей, не только молодые по возрасту, но совершенно иные по своим ценностным ориентациям.

К середине 1930-х годов, когда Сталин отрапортовал, что в СССР в основном и целом построен социализм, должен был бы завершиться процесс статусной кристаллизации, т.е. в основном и целом должна была сформироваться новая социальная структура, все вакансии, в которой были бы заняты. Однако именно в это время разворачивается мощный деструктивный процесс, включающий в себя:

а) раскулачивание огромных крестьянских масс;

б) политические репрессии, применявшиеся по отношению к рабочим и интеллигенции.

В течение короткого исторического периода с 1933 по 1939 г. в стране были раскулачены и репрессированы миллионы людей. В результате, на высших и средних позициях в социальной структуре вновь образовалось значительное число вакансий. Их заполнение еще не успело завершиться, как страна вступила во Вторую Мировую Войну, по окончании которой из социального состава населения было выбито около 30 миллионов человек. Нарушилось не только демографическое воспроизводство общества, но и второй процесс кристаллизации социальной структуры.

В период второй мировой войны и последовавшие за нею несколько лет восстановления народного хозяйства высшие и средние позиции в социальной структуре заняло новое поколение руководителей и интеллигенции. Общество стало свидетелем второго всплеска вертикальной мобильности. Этот процесс плавно продолжался также в 1960-е годы, но причины интенсивной мобильности в обществе на этот раз были иными. Массовые политические чистки ушли в прошлое. Согласно стратегическим установкам КПСС страна активно создавала материально-техническую базу коммунизма. Это означало строительство сотен и тысяч новых хозяйственных объектов по всей территории страны. На смену интенсивной вертикальной мобильности приходит интенсивная горизонтальная. Осваивать целину в Казахстане, строить гигантские гидроэлектростанции в Сибири и возводить великие стройки коммунизма выезжали сотни тысяч молодых людей из центральной России.

К середине 1970-х годов интенсивная вертикальная и горизонтальная мобильность затухают. Начинается третий этап кристаллизации социальной структуры. Доказательством служат появившиеся в это время социологические концепции самовоспроизводства рабочего класса и внутриклассовой 
дифференциации. О чем идет речь. Согласно первой теории советский рабочий класс на 70-80\% воспроизводился за счет производителей городского рабочего класса. Его ряды уже не пополняло как прежде крестьянство. Последние как демографический источник пополнения средних классов в 1970-80-е годы благодаря оттоку людей из села в город сократились до угрожающе малой величины. И хотя по прежнему на селе у нас проживало гораздо больше, а именно 23-27\% населения, чем в развитых странах, где этот показатель сократился до 5$7 \%$, численность сельского населения оказалась недостаточной для того, чтобы прокормить всю страну.

Огромные закупки зерна за рубежом свидетельствуют о том, что наше сельское хозяйство, несмотря на его высокую механизацию, не соответствовало передовым достижениям науки и техники. По существу оно оставалось раннеиндустриальным, хотя промышленность перешла уже на следующую стадию среднего и позднего индустриального развития.

В начале 1990-х годов мы становимся свидетелями третьего деструктивного процесса. В связи с переходом страны от социализма к капитализму, в социальной структуре общества происходят кадровые перемещения в верхней и средней позициях. Новое демократическое поколение, совершившее мирную революцию вытеснило с командных высот старую коммунистическую гвардию. Однако в обществе происходили не только количественные, но и качественные изменения. На смену социалистическому типу стратификации, который некоторые социологи условно именуют сословно-корпоративным строем пришел новый тип стратификации - классовый. По существу это было второй попыткой в истории построить на территории нашей страны классовое общество капиталистического типа. Первая незавершившаяся попытка проходила в период с 1861 по 1917 год.

Наше общество так и не смогло построить ни экономический, ни социальный, ни политический фундамент капитализма. Экономически неудачной эту попытку следует назвать потому, что:

a) в стратификационной системе класс буржуазии так и не смог вытеснить с командных высот дворянское сословие; б) численность рабочего класса, основной движущей силы индустриального общества в России оставалась удручающе малой по сравнению с Западными странами.

Вторая попытка создания классового общества в России, начавшаяся в 1991 году происходила на качественно ином фундаменте. Если в первой попытке классовому обществу предшествовало сословно-феодальное, победить которое так и не удалось, то во второй попытке классовому строю предшествовало так 
называемое бесклассовое общество советского типа, которое состояло из двух дружественных классов (рабочие и крестьяне) и прослойки между ними.

Поскольку советское общество нельзя четко отнести не к одному из четырех известных исторических типов стратификации, а именно рабству, кастам, сословиям и классам, то не о какой статусной кристаллизации и внутреннем единстве социальной структуры говорить не приходится. Социальная структура советского общества напоминала скорее жидкий кристалл. Именно поэтому ее безболезненно и мирным путем удалось разрушить в короткие исторические сроки.

В течение 70 лет советской власти наблюдались два противоположных социальных процесса. В то время как численность рабочего класса и крестьянства постепенно сокращалась, особенно заметно крестьянства, численность среднего класса, выросшего из прослойки интеллигенции, возрастала. Тому есть две причины:

научно-технический процесс вынудил нашу страну развивать авангардные наукоемкие индустрии, одновременно расширяя сеть средних и высших учебных заведений;

происходившее в течение семидесяти лет неуклонное укрепление и расширение численности административной системы.

Советская власть, как и все советское общество, оказалась историческим заложником самой мощной в мире властной вертикали, основу которой составляло в начале царское чиновничество, а позже коммунистическая номенклатура.

Именно эти две составляющие российского общества внесли наибольший вклад в формирование среднего класса. Можно считать, что его главной силой является административная система с еe разветвленным управленческим аппаратом и многочисленной обслуживающей прослойкой. Вторая менее значимая, но постоянно возрастающая составляющая среднего класса - это научно-техническая интеллигенция плюс новые рыночные слои.

Благодаря этим двум составляющим средний класс России имеет историческую специфику. В Западных обществах доля чиновников и властной вертикали в среднем классе минимальна, а численность научно-технических и рыночных слоев максимальна.

Когда российские социологи в середине 1990-х годов занялись активным изучением средних классов России, то большинство из них с сожалению констатировало, что их доля очень мала или практически отсутствует. По 
большинству расчетов доля среднего класса не превышала $12-15 \%$. В сущности, российские социологи искали в нашем обществе аналог Западного среднего класса, а потому его не находили. Меньшинство отечественных социологов считало, что в России должен существовать собственный средний класс, не во всем походящий на западный и отражающий историческое своеобразие нашей страны. Это наиболее правильный подход.

Если мы перестанем искать механические аналоги западного среднего класса и проанализируем его сущностные признаки, то увидим, что начиная с Платона и Аристотеля к среднему классу относили тех, кто занимался творческим, физическим и умственным трудом, считался самозанятым, а главное, - являлся социальным стабилизатором общества. Чем многочисленнее средний класс, тем благополучнее является общество и наоборот.

Античное общество достигло своего расцвета именно во времена Платона и Аристотеля. Демократия органично сочеталась с задатками рыночной или полу - рыночной экономики. Сходная картина наблюдалась в советском обществе в 1970-80-е годы. Закончились массовые репрессии. Благодаря косыгинской реформе 1968 года в экономике появились элементы рыночной свободы. Благодаря периоду хрущевской «оттепели» (1954-1964) в стране стали возрождаться некоторые институты демократического общества. Наряду с этим экономика страны в 1960-70-е годы переживала самые высокие темпы роста в своей истории. Повысилось материальное благосостояние народа. Все это заложило фундамент для формирования среднего класса советского типа. Если не считать 3-5\% крайне обеспеченной верхушки и 5-7\% крайне необеспеченных низов, то в основную часть населения с известными оговорками можно зачислить ту зону, где распределился средний класс или средние слои общества. Под средними слоями надо понимать статистические категории, которые выделяются по уровню доходов, но не имеют общего классового сознания. Под средним классом надо понимать реальную группу, которая выделяется не только и не столько уровнем жизни, сколько наличием соответствующего классового сознания, образа жизни и культуры.

Мощное развитие системы высшего образования в 1960-70-е годы, возможно, самое высокое в мире, позволило создать в нашей стране огромную прослойку грамотных людей, но она не стала господствовать, потому, что общий уровень грамотности в России всегда отставал от стран Запада. 